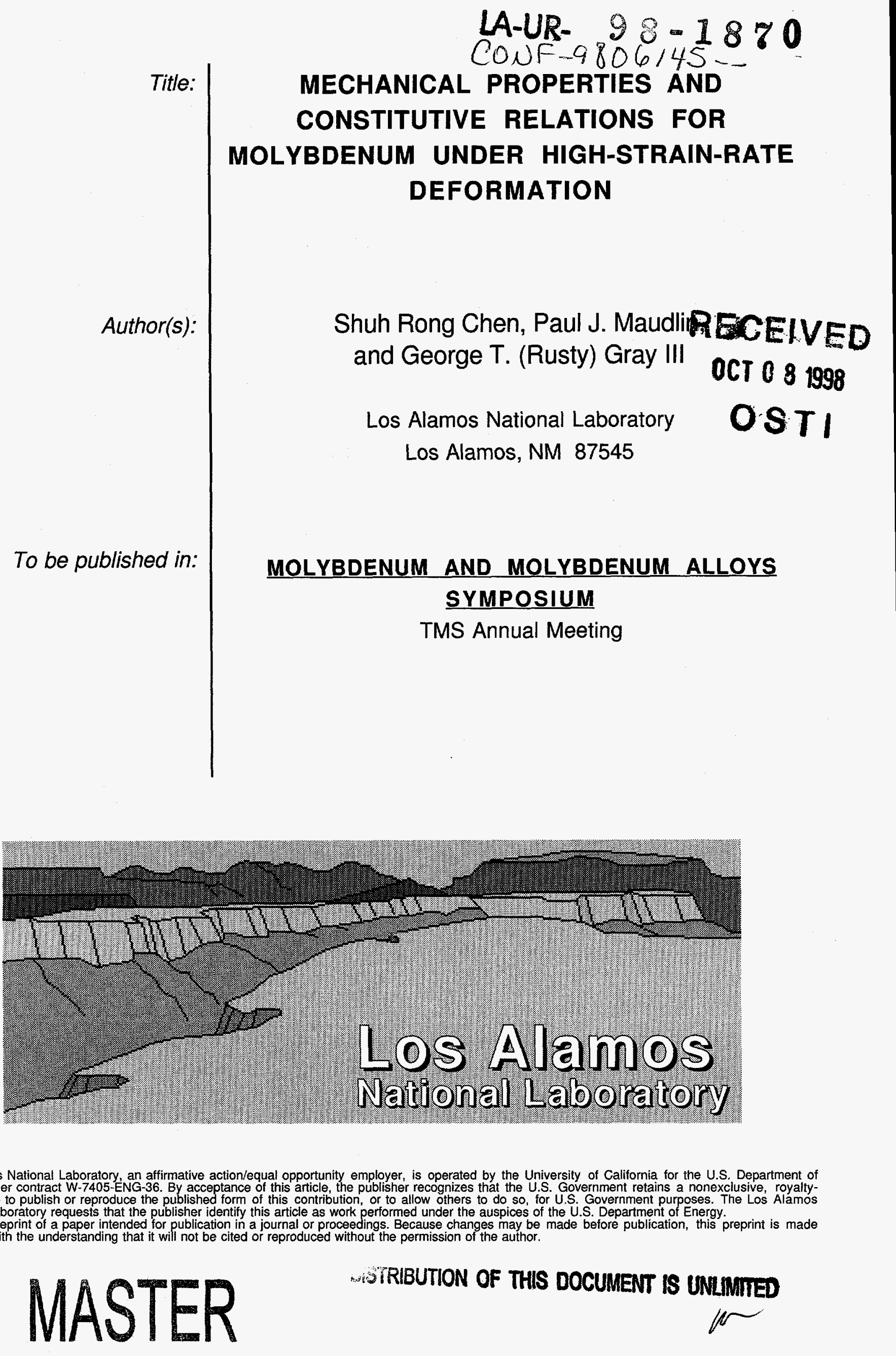

Los Alamos National Laboratory, an affirmative action/equal opportunity employer, is operated by the University of California for the U.S. Department of Energy under contract W-7405-ENG-36. By acceptance of this article, the publisher recognizes that the U.S. Government retains a nonexclusive, royaltyfree license to publish or reproduce the published form of this contribution, or to allow others to do so, for U.S. Government purposes. The Los Alamos National Laboratory requests that the publisher identify this article as work performed under the auspices of the U.S. Department of Energy.

This is a preprint of a paper intended for publication in a journal or proceedings. Because changes may be made betore publication, this preprint is made available with the understanding that it will not be cited or reproduced without the permission of the author. 


\section{DISCLAIMER}

This report was prepared as an account of work sponsored by an agency of the United States Government. Neither the United States Government nor any agency thereof, nor any of their employees, makes any warranty, express or implied, or assumes any legal liability or responsibility for the accuracy, completeness, or usefulness of any information, apparatus, product, or process disciosed, or represents that its use would not infringe privately owned rights. Reference berein to any specific commercial product, process, or service by trade name, trademark, manufacturer, or otherwise does not necessarily constitute or imply its endorsement, recommendation, or favoring by the United States Government or any agency thereof. The views and opinions of authors expressed herein do not necessarily state or reflect those of the United States Government or any agency thereof. 


\section{DISCLAIMER}

Portions of this document may be illegible in electronic image products. Images are produced from the best available original document. 


\title{
MECHANICAL PROPERTIES AND CONSTITUTIVE RELATIONS FOR MOLYBDENUM UNDER HIGH-RATE DEFORMATION
}

\author{
Shuh Rong Chen, Paul J. Maudlin, and G.T. (Rusty) Gray III \\ Los Alamos National Laboratory \\ Los Alamos, New Mexico 87545
}

\begin{abstract}
Molybdenum and its alloys have received increased interest in recent years for ballistic applications. The stress-strain behavior of several molybdenums possessing various compositions, manufacturing sources, and the degree of pre-straining, were investigated as a function of temperature from 77 to $1273 \mathrm{~K}$, and strain rate from $10^{-3} \mathrm{~s}^{-1}$ to $8000 \mathrm{~s}^{-1}$. The yield stress was found to be sensitive to the test temperature and strain rate, however, the strain hardening remained rate-insensitive. The constitutive response of a powder-metallurgy molybdenum was also investigated; similar mechanical properties compared to conventionally wrought processed molybdenums were achieved. Constitutive relations based upon the JohnsonCook, the Zerilli-Armstrong and the Mechanical Threshold Stress (MTS) models were evaluated and fit for the various Mo-based materials. The capabilities and limitations of each model for largestrain applications were examined. The differences between the three models are demonstrated using model comparisons to Taylor cylinder validation experiments
\end{abstract}

\section{Introduction}

Molybdenum and its alloys is increasingly being utilized in defense-related applications ${ }^{[1]}$ where its mechanical properties under high-strain-rate deformation has proven desirable. In this paper a wide range of data on molybdenums and powder-metallurgy molybdenums subjected to highstrain-rate compression at various temperatures are presented. The yield and flow stresses for four Mo materials studied are shown to be sensitive to changes in temperature and strain rate at low temperatures and/or high strain rates. A large Peierls stress in bcc materials has been proposed as the rate-controlling mechanism in this temperature and strain-rate regime ${ }^{[2,3]}$. This large intrinsic lattice resistance results in restricted movement of screw dislocations; long straight screw segments are often observed in this class of materials after deformation ${ }^{[3-5]}$. This suppression of cross-slip of screw dislocations results in linear glide and therefore lower overall strain-hardening rates ${ }^{[6]}$. Strain hardening rates in this class of materials under low temperature or high strain rates loading states are also seen to be temperature insensitive and to first order strain independent $[3,7]$.

The strain hardening behavior of metals at high strain rate is complicated by thermal softening due to adiabatic heating as a result of plastic work with no time for dissipation. Acquiring the dynamic isothermal hardening behavior has been done through incremental tests in the Hopkinson bar for a tantalum material[ ${ }^{8]}$. Due to further work hardening to the sample and the change in dimension, it was difficult to control the sequential tests at the same strain rate and to maintain a constant strain rate to large strains. In this study, low-temperature quasi-static compression tests are conducted to obtain the strain hardening response of various molybdenum materials. Based on thermal activation theory $[6,9-14]$, the strain hardening behavior of a quasi-static low-temperature test is compared to that of a high-rate reloading test. The validity of using quasi-static low temperature tests as an alternative to obtain the strain hardening behavior at high strain rate to large strains under better controlled test conditions is discussed in this paper.

The widespread utilization of modern high-speed computers makes it possible to develop more sophisticated material constitutive model descriptions capable of modeling complex problems ${ }^{15-}$ 
18]. An accurate description of a materials response over a wide range of loading environments, as well as having predictive capabilities outside the measured range, is in great demand. The material properties unique to bcc metals and alloys bring many challenges to the development of physicallybased constitutive models. Several currently utilized constitutive models, namely the Mechanical Threshold Stress model[19], the Johnson-Cook model[20], and the Zerilli-Armstrong model[21], were examined. The same data set is used to derive the parameters for each model enabling direct comparisons between each model for a fixed validation experiment, namely a Taylor cylinder test.

\section{Experimental}

\section{Materials}

Four commercially-pure molybdenums were investigated in this study. Two molybdenum plates were produced via conventional casting and wrought processes. The as-received plate, designated as Mo-C, was recrystallized and then received $20 \%$ work (designated as $\mathrm{Mo}-\mathrm{C} 20$ ). The other two molybdenums were manufactured via powder metallurgy $(\mathrm{P} / \mathrm{M})$ by isostatically pressing Mo powder and subsequently sintering at high temperature. The first $\mathrm{P} / \mathrm{M} \mathrm{Mo}$ as sintered bar (designated as $\mathrm{P} / \mathrm{M}-\mathrm{Mo}$ ) was not fully dense, $95.4 \%$ of theoretical density. However, subsequent forging leads to densification to theoretical density. The second $P / M$ Mo received $20 \%$ work after sintering to yield a fully dense microstructure (designated as P/M-Mo-20 thereafter).

The mechanical responses of these molybdenum materials were measured in compression using solid-cylindrical samples nominally $5-\mathrm{mm}$ in diameter by 5 -mm long, lubricated with molybdenum disulfide grease. Quasi-static compression tests were conducted at strain rates between $10^{-3}$ and $10^{-1} \mathrm{~s}^{-1}$ at $-196^{\circ} \mathrm{C},-140^{\circ} \mathrm{C},-90^{\circ} \mathrm{C}$, and $25^{\circ} \mathrm{C}$. Dynamic tests, strain rates of $1000-8000 \mathrm{~s}^{-1}$, were conducted from $-196^{\circ} \mathrm{C}$ to $1000^{\circ} \mathrm{C}$ in vacuum utilizing a Split-Hopkinson Pressure Bar. [22] The inherent oscillations in the dynamic stress-strain curves and the lack of stress equilibrium in the specimens at low strains make the determination of yield inaccurate at high strain rates.

\section{Description of Models}

The constitutive equations used in this study are as follows:

Johnson-Cook Model (JC):[20]

$$
\sigma=\left(A+B \cdot \varepsilon_{p}{ }^{n}\right)\left(1+C \cdot \ln \dot{\varepsilon}^{*}\right)\left(1-T^{* m}\right)
$$

where $\dot{\varepsilon}^{*}$ is a non-dimensional strain rate value, $\varepsilon_{p}$ is the plastic strain, and $T^{*}$ is defined as $\left(\mathrm{T}-\mathrm{T}_{\text {Room }}\right) /\left(\mathrm{T}_{\text {Melt }}-\mathrm{T}_{\text {Room }}\right)$.

Zerilli-Armstrong Model (ZA) for body-centered cubic material:[21]

$$
\sigma=C_{0}+C_{1} \cdot \exp \left(-C_{3} \cdot T+C_{4} \cdot T \cdot \ln \dot{\varepsilon}\right)+C_{5} \cdot \varepsilon_{p}{ }^{n}
$$

The athermal stress term $C_{0}$ can be modified to include grain size effects using a Hall-Petch relation $\sigma_{0}+k \cdot d^{-1 / 2}$, where $d$ is the average grain size. In the ZA model, it is presumed that the work hardening rate is independent of temperature and strain rate. Both the $\mathrm{JC}$ and $\mathrm{ZA}$ models use a power-law stress-strain relationship that exhibits continual work hardening without approaching a saturation stress at large strains; i.e., both models predict infinite stresses at infinite strains.

\section{Mechanical Threshold Stress Model (MTS):}

The fundamental dislocation kinetics theories underpinning this model and detailed description of the mechanical threshold stress (MTS) model have been presented in detail previously[19,23-25]. A brief summary of the equations used in the MTS model is presented here. Plastic deformation is known to be controlled by the thermally-activated interactions of dislocations with obstacles. In the MTS model the current structure at any point during the deformation process is represented by 
an internal state variable, the mechanical threshold which is defined as the flow stress at $0 \mathrm{~K}$. This mechanical threshold stress is separated into athermal and thermal components. The athermal component characterizes the rate independent interactions of dislocations with long-range barriers such as grain boundaries or second-phase particles or dispersoids, such as in composites. The thermal component characterizes the rate dependent interactions of dislocations with short range obstacles (forest dislocations, interstitial, solutes, Peierls barrier, etc.) that can be overcome with the assistance of thermal activation. The stress of a constant structure at a given deformation condition can be expressed in terms of the mechanical threshold as

$$
\frac{\sigma}{\mu}=\frac{\sigma_{a}}{\mu}+\sum S(\dot{\varepsilon}, T) \frac{\hat{\sigma}_{t}}{\mu_{0}},
$$

where the athermal component is a function of temperature only through the shear modulus $(\mu)$, and the factor $S$ specifies the ratio between the applied stress and the mechanical threshold stress. This factor is smaller than 1 for thermally activated controlled glide because of the contribution of thermal activation. The form for $S$ is written as $[6]$ :

$$
S=\left[1-\left(\frac{k T}{g_{0} \mu b^{3}} \ln \frac{\dot{\varepsilon}_{0}}{\dot{\varepsilon}}\right)^{1 / q}\right]^{1 / p} .
$$

For single phase materials with cubic crystal structures, the thermal component consists of the linear summation of a term describing the yield stress and a term describing the evolution of the dislocation structure as a function of temperature, strain rate and strain. Equation (3) can be written as

$$
\frac{\sigma}{\mu}=\frac{\sigma_{a}}{\mu}+S_{i}(\dot{\varepsilon}, T) \frac{\hat{\sigma}_{i}}{\mu_{0}}+S_{\varepsilon}(\dot{\varepsilon}, T) \frac{\hat{\sigma}_{\varepsilon}}{\mu_{0}} .
$$

The second term on the right hand side of the equation describes the rate dependence of the yield stress mainly due to intrinsic barriers such as the strong Peierls stress observed in bcc materials at low temperatures or at high strain rates. It is further assumed that this term doesn't evolve after yielding. $\hat{\sigma}_{\varepsilon}$ in equation (5) evolves with strain due to dislocation accumulation (work hardening) and annihilation (recovery). The physical understanding of the work hardening behavior of polycrystals is still inadequate to unify this complex process and represent it by physically-based parameters. Follansbee et al.[19] have chosen the following form to fit the work hardening to their experimental data:

$$
\theta=\theta_{0}\left\{1-\frac{\tanh \left[\alpha \frac{\hat{\sigma}_{\varepsilon}}{\hat{\sigma}_{\varepsilon s}(\dot{\varepsilon}, T)}\right]}{\tanh (\alpha)}\right\}
$$

where $a$ approaches zero represents a linear variation of strain hardening rate with stress (Voce law). The saturation threshold stress $\hat{\sigma}_{\varepsilon s}$ is a function of temperature and strain rate according to:[26-28]

$$
\hat{\sigma}_{\varepsilon s}=\hat{\sigma}_{\varepsilon s 0}\left(\frac{\dot{\varepsilon}}{\dot{\varepsilon}_{\varepsilon s 0}}\right)^{1 / n}
$$

where $n=g_{0 \varepsilon s} \mu b^{3} / k T, \dot{\varepsilon}_{\varepsilon s 0}, g_{0 \varepsilon s}$, and $\hat{\sigma}_{\varepsilon s 0}$ are constants.

The shear modulus was calculated for body-centered cubic (bcc) Mo using the formula: 


$$
\mu=\frac{\left(C_{11}-C_{12}+C_{44}\right)}{3}
$$

where $C_{i j}$ are the elastic constants ${ }^{[29]}$. For simplicity, an empirical equation ${ }^{[30]}$ was used to fit the data to incorporate the temperature dependence of " $\mu$ " in a form of

$$
\mu=\mu_{0}-\frac{D}{\exp \left(\frac{T_{0}}{T}\right)-1} .
$$

The temperature rise for the tests at strain rates above $500 \mathrm{~s}^{-1}$ can be calculated assuming a certain percentage $(\Psi)$ of the work of plastic deformation is converted into heat according to:

$$
\Delta T=\frac{\Psi}{\rho C_{p}} \int \sigma(\varepsilon) d \varepsilon
$$

where $\sigma$ and $\varepsilon$ are the true stress and strain, $\rho$ is the density, and $C_{p}$ is the heat capacity that can be written in the form $\left.{ }^{[31}\right]$ of

$$
A_{0}+A_{1} \cdot T+A_{2} / T^{2} .
$$

Adiabatic heating is expected to make a large difference at higher strains during high-rate deformation.

\section{Results and Discussions}

\section{Mechanical Responses}

The effect of temperature and strain rate on the mechanical properties of the Mo-materials was investigated through a series of compression tests over a wide range of temperatures and strain rates. The compressive stress-strain responses of the four different Mo materials are shown in Figures 1-4.

A few common attributes were seen to be exhibited in all four sets of experimental data: 1) below $600^{\circ} \mathrm{C}$ at high strain rates, the yield stress is very sensitive to the testing temperature and strain rate, 2) most of the strain-stress curves showed mild stress drops immediately after yielding, the magnitude of this stress decrease depended strongly on the strain rate, 3) all the materials hardened after yielding; however the rate of change in the flow stress at a certain strain is insensitive to both temperature and strain rate for tests below $\sim 400^{\circ} \mathrm{C}$ at high rates, and 4) at $-196^{\circ} \mathrm{C}$ and at $0.001 / \mathrm{s}$, the yield stress and work hardening rate are substantially higher than those at and above $25^{\circ} \mathrm{C}$. This observation suggests that deformation twinning may be occurring in addition to slip. Observations 1 and 3 are unique to materials with a body-centered-cubic structure. This behavior is primarily due to a strong Peierls barrier which is an intrinsic property of bcc metals as well as other lower symmetry materials. Through thermal activation processes, this intrinsic barrier becomes transparent to dislocation motion at higher temperatures. The dependence of the flow stress on temperature therefore dramatically decreases (dynamic tests at 200,600 and $1000^{\circ} \mathrm{C}$ in Figure 1). On the contrary, for an annealed face-centered-cubic material (e.g., OFE-Cu or Ni-270) the yield stress weakly depends on the temperature and strain rate. In addition, the stress-strain curves at different temperatures and strain rates diverge upon further deformation indicating that their strain hardening behavior is rate dependent ${ }^{[32-34]}$. The dynamic stress-strain behavior at $196^{\circ} \mathrm{C}$ is somewhat ambiguous such that the work hardening. rate decreases much faster starting in earlier part of deformation. This was mainly due to the amount of cold work introduced into the materials that raised the flow stress substantially. The high flow stress made it difficult to maintain a constant strain rate during Hopkinson pressure bar testing. The degree of difference observed between the quasi-static and dynamic cryogenic tests is seen to be minor for Mo-C20 and P/M-Mo. 


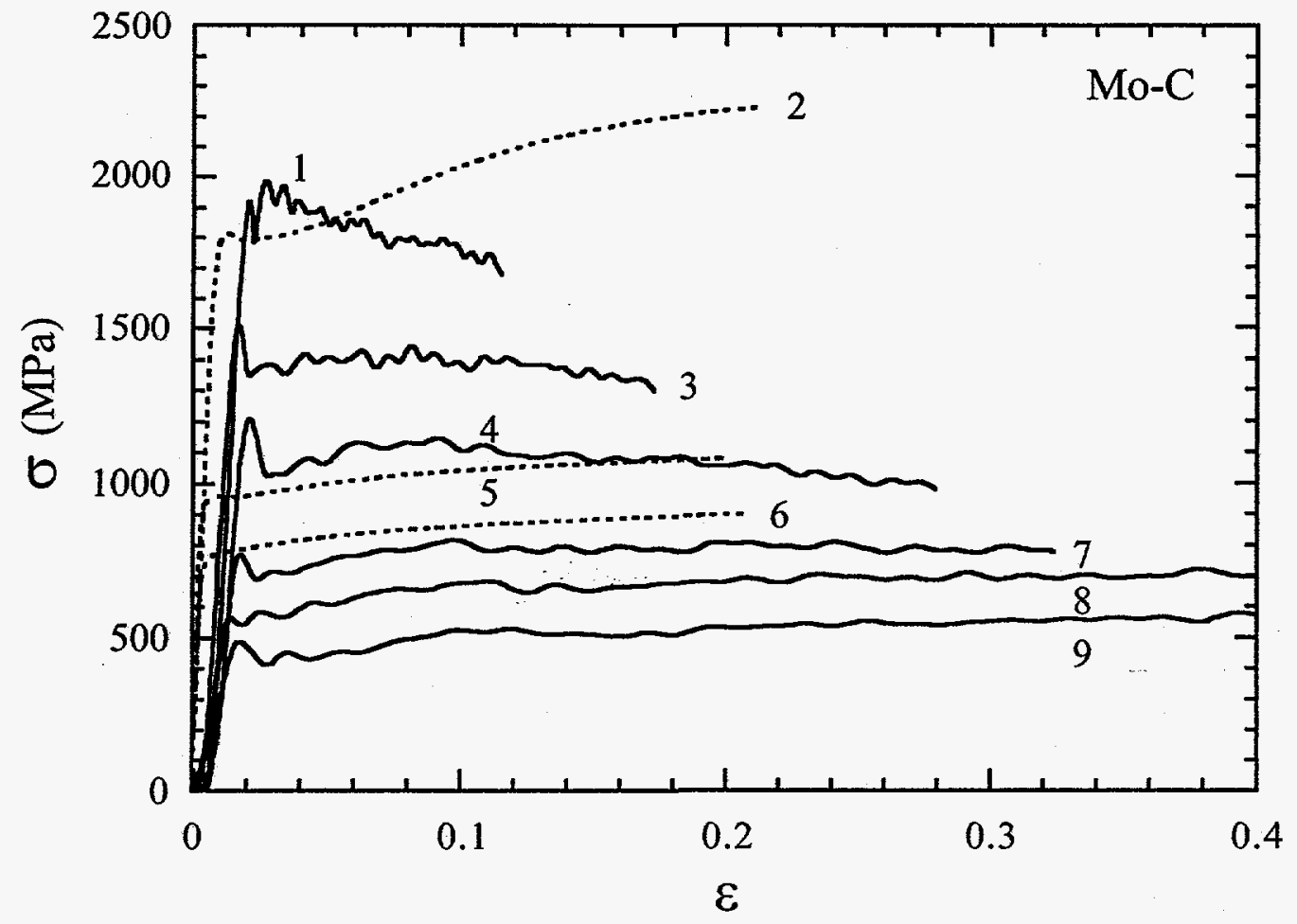

Figure 1: Compressive stress-strain response of the Mo-C plate material. The test temperature and strain rate for each curve: $1 .-196^{\circ} \mathrm{C}, 1300 / \mathrm{s} ; 2 .-196^{\circ} \mathrm{C}, 10^{-3} \mathrm{~s}^{-1} ; 3.25^{\circ} \mathrm{C}$, $1800 / \mathrm{s} ; 4.200^{\circ} \mathrm{C}, 3000 / \mathrm{s} ; 5.25^{\circ} \mathrm{C}, 10^{-1} \mathrm{~s}^{-1} ; 6.25^{\circ} \mathrm{C}, 10^{-3} \mathrm{~s}^{-1} ; 7.400^{\circ} \mathrm{C}, 3400 / \mathrm{s} ; 8.600^{\circ} \mathrm{C}$, $4200 / \mathrm{s} ; 9.1000^{\circ} \mathrm{C}, 4500 / \mathrm{s}$.

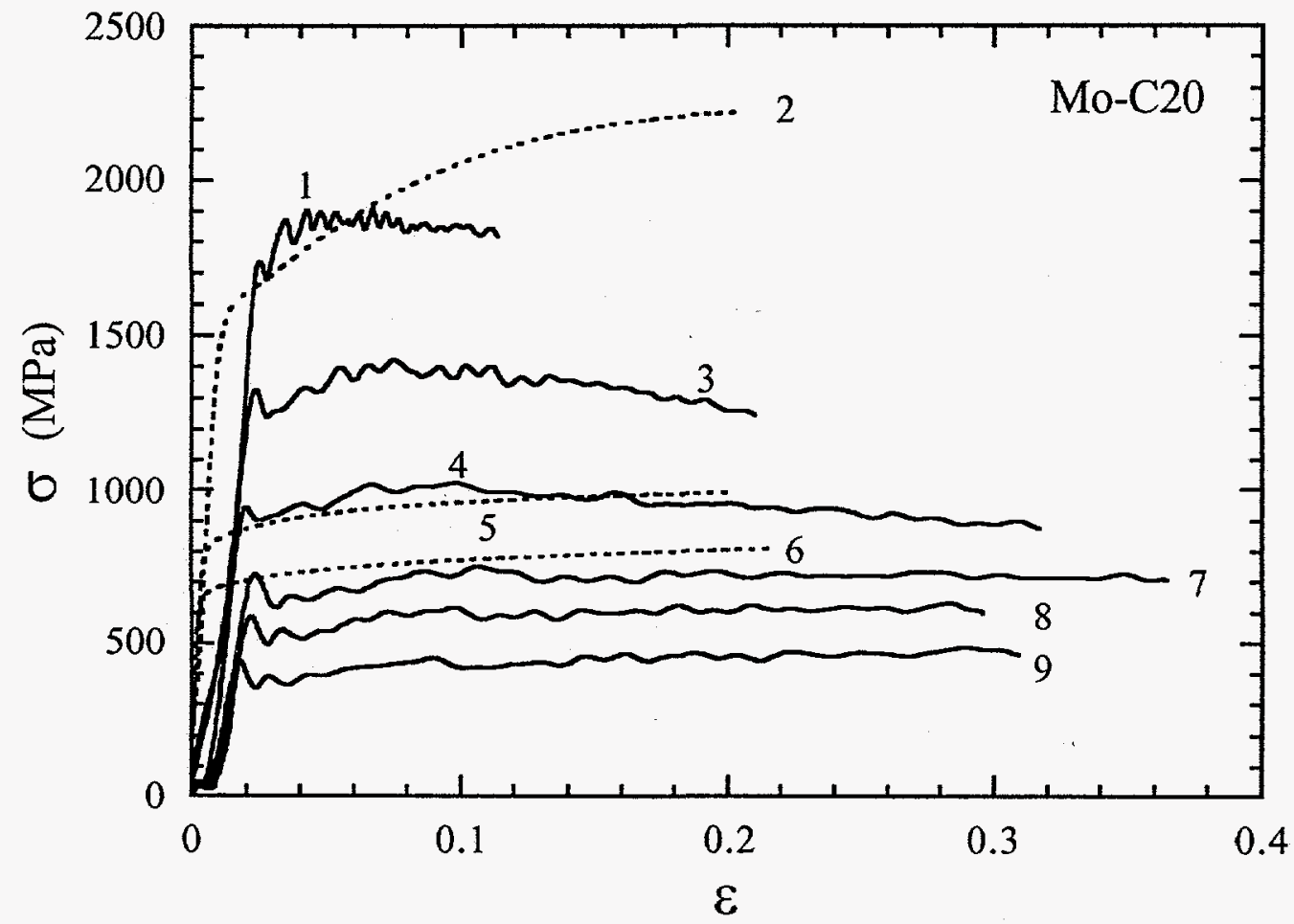

Figure 2: Compressive stress-strain response of the Mo-C20 plate material. The test temperature and strain rate for each curve: $1 .-196^{\circ} \mathrm{C}, 1000 / \mathrm{s} ; 2 .{ }^{\circ}-196^{\circ} \mathrm{C}, 10^{-3} \mathrm{~s}^{-1} ; 3.25^{\circ} \mathrm{C}$, $2000 / \mathrm{s} ; 4.200^{\circ} \mathrm{C}, 3300 / \mathrm{s} ; 5.25^{\circ} \mathrm{C}, 10^{-1} \mathrm{~s}^{-1} ; 6.25^{\circ} \mathrm{C}, 10^{-3} \mathrm{~s}^{-1} ; 7.400^{\circ} \mathrm{C}, 3800 / \mathrm{s} ; 8.600^{\circ} \mathrm{C}$, $3000 / \mathrm{s} ; 9.1000^{\circ} \mathrm{C}, 3200 / \mathrm{s}$. 


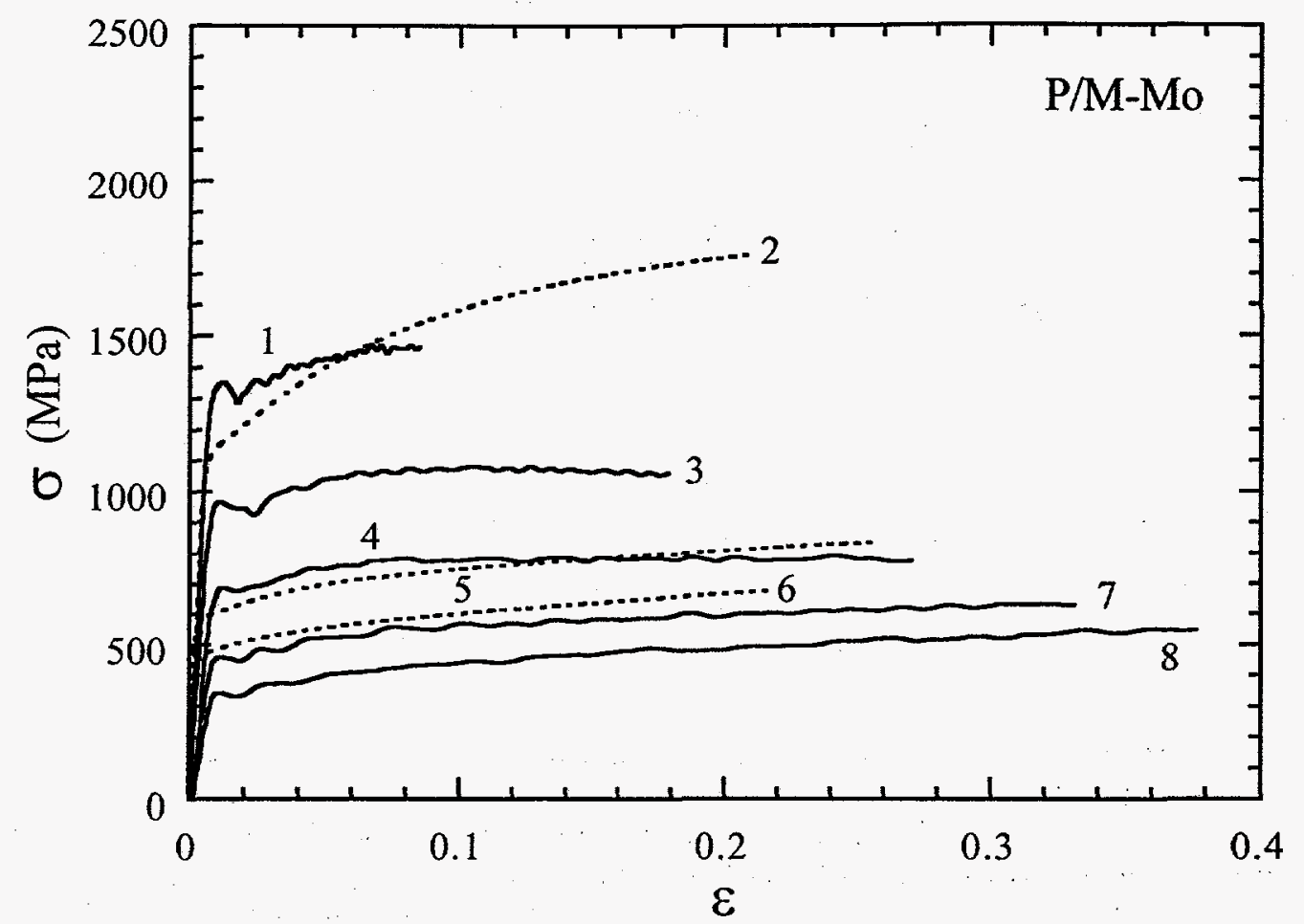

Figure 3: Compressive stress-strain response of the P/M-Mo bar material. The test temperature and strain rate for each curve: $1 .-196^{\circ} \mathrm{C}, 1500 / \mathrm{s} ; 2 .-196^{\circ} \mathrm{C}, 10^{-3} \mathrm{~s}^{-1} ; 3.25^{\circ} \mathrm{C}$, $2000 / \mathrm{s} ; 4.200^{\circ} \mathrm{C}, 3000 / \mathrm{s} ; 5.25^{\circ} \mathrm{C}, 10^{-1} \mathrm{~s}^{-1} ; 6.25^{\circ} \mathrm{C}, 10^{-3} \mathrm{~s}^{-1} ; 7.400^{\circ} \mathrm{C}, 3800 / \mathrm{s} ; 8.600^{\circ} \mathrm{C}$, $4000 / \mathrm{s}$.

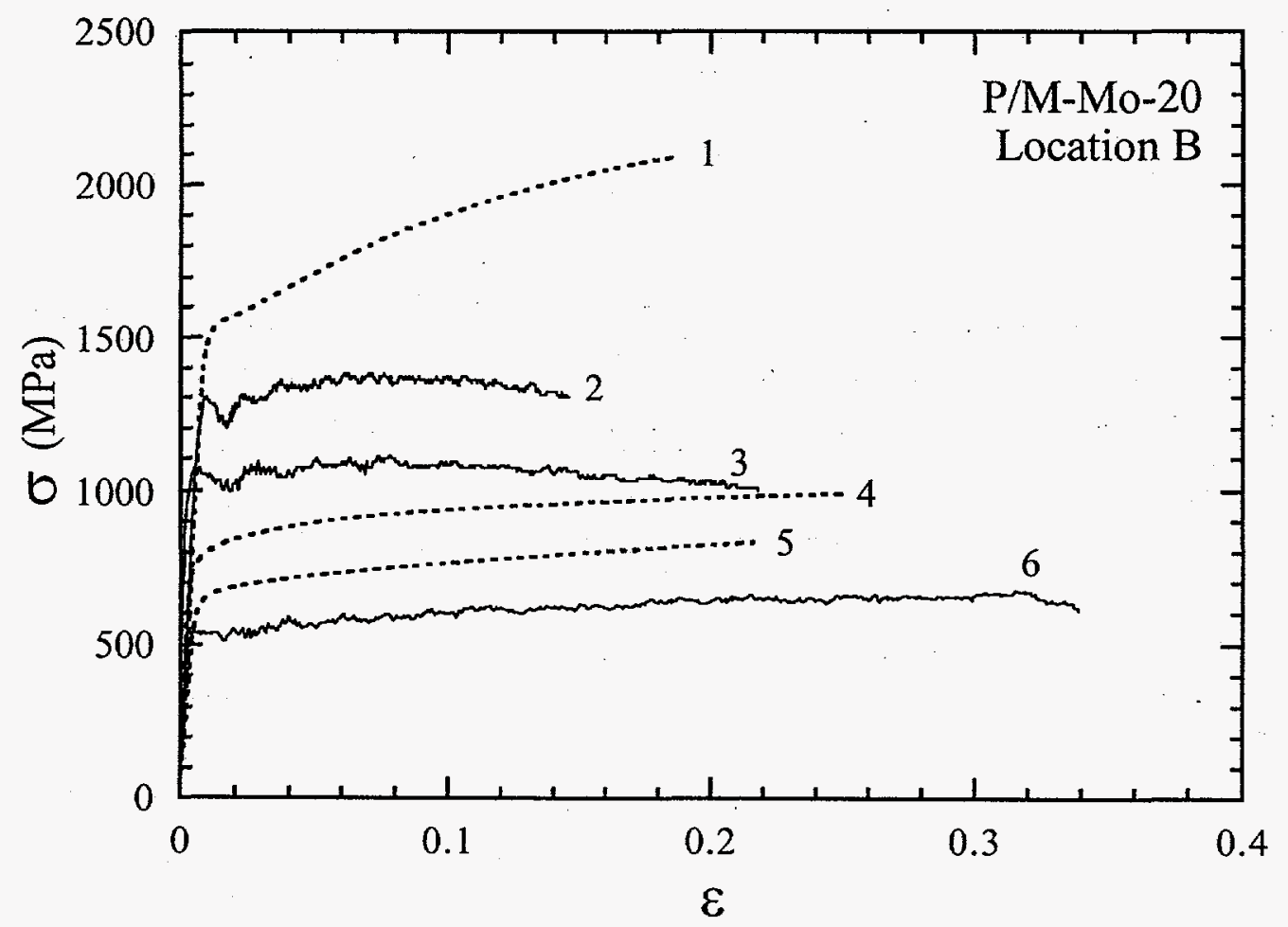

Figure 4: Compressive stress-strain response of the P/M-Mo-20 plate material. The test temperature and strain rate for each curve: $1 .-196^{\circ} \mathrm{C}, 10^{-3} \mathrm{~s}^{-1} ; 2.25^{\circ} \mathrm{C}, 1500 / \mathrm{s} ; 3.200^{\circ} \mathrm{C}$, $2500 / \mathrm{s} ; 4.25^{\circ} \mathrm{C}, 10^{-1} \mathrm{~s}^{-1} ; 5.25^{\circ} \mathrm{C}, 10^{-3} \mathrm{~s}^{-1} ; 6.600^{\circ} \mathrm{C}, 3400 / \mathrm{s}$. 
The reproducibility and homogeneity of the P/M-Mo plate was evaluated through repeated tests at three different strain rates at room temperature. Samples were also machined from three different locations (about $50 \mathrm{~mm}$ apart from one another) in the plate. Fig. 5 shows the flow stresses as a function of strain rate and location. The stress-strain curves were seen to lie within the experimental scatter. The high strain-rate sensitivity of the yield stresses exhibited in this class of materials is further demonstrated in Fig. 5.

The mechanical responses from the four Mo materials investigated in this study are compared at $25^{\circ} \mathrm{C}$ and at $10^{-3} \mathrm{~s}^{-1}$ (Fig. 6). The amount of work retained from the first processing is seen to be higher than $20 \%$ as displayed by the higher flow stress of Mo-C as compared to that of Mo-C20. The as-sintered P/M-Mo bar exhibits the lowest yield and flow stresses mainly due to its annealed initial microstructure. Both the conventionally and powder-metallurgy processed Mo after $20 \%$ work show very similar flow behaviors (curves labeled as Mo-C20 and P/M-Mo-20, respectively, in Fig. 6). The powder-metallurgy process provides an alternate route to produce a homogeneous and isotropic material having comparable mechanical properties.

\section{Constitutive Modeling of P/M-Mo-20 plate}

\section{Johnson-Cook and Zerilli-Armstrong Models:}

For the JC and ZA models, computer programs were developed ${ }^{25,35]}$ to optimize the fitting constants to the stress-strain data over a wide range of temperatures and strain rates. The best fit to the JC model for the P/M-Mo-20-plate material is shown in Figure 7. The experimental data at strains less than 0.1 were treated as representing an isothermal condition for all strain rates. The effect of adiabatic heating at high strain rates was neglected for low strains. This is appropriate since the strain hardening rate in bcc materials is very insensitive to the strain rate and temperature. The strain hardening behavior can be obtained from a quasi-static test where adiabatic heating is not significant. This will be presented in the next section describing the strain hardening behavior at high rates and large-strain behavior. The formulation of the JC model (equation (1)) which was originally derived for fcc metals, presumes the stress-strain curves diverge upon deformation as is typical for metals such as $\mathrm{Cu}$ and $\mathrm{Ni}$. In order to capture the strain hardening behavior at finite strains past yield, the starting yield stresses calculated from the model (bracketed by two arrows in Fig. 7) must be set to be much lower than the actual experimental data suggested. Otherwise, because of this intrinsic divergence the flow stress at larger strains, the flow stresses at higher strains would be significantly over predicted. The overall flow stresses and strain hardening (especially at $25^{\circ} \mathrm{C}$ and at $0.1 / \mathrm{s}$ ) are seen to be reproduced satisfactorily by this model. The flow stresses at high strain rate was calculated assuming adiabatic condition with $95 \%$ of the work converted into heat. The temperature rise due to adiabatic heating softens the material at higher strains. Because of a very simplistic form used in the model to describe the temperature softening effect, the flow stress at $600^{\circ} \mathrm{C}$ is seen to be over-predicted (inverse triangles compared to the short dashed line in Fig. 7). It can be adjusted to capture the temperature sensitivity for the $600^{\circ} \mathrm{C}$ condition, but then it will under predict the mechanical response at $200^{\circ} \mathrm{C}$. The final optimization of the model fit will depend on the ranges of strains, strain rates, and temperatures actually observed in real applications. Furthermore, the strain hardening rate is insensitive to the strain rate and temperature change in unalloyed bcc materials, like Mo, within the range investigated. Substantial deviation from the experimental data for the JC model is expected to be larger at higher strains due to the flow stress divergence of the model with strain.

The ZA model assuming rate-independent strain hardening and a rate-dependent yield stress for bcc metals (equation (2)). The fitting results for the P/M-Mo-20-plate material to the ZA model shown in Fig. 8 are in close agreement with the experimental data for strain rates from $10^{-3} \mathrm{~s}^{-1}$ to $3400 \mathrm{~s}^{-1}$, and temperatures ranging from $25^{\circ} \mathrm{C}$ to $600^{\circ} \mathrm{C}$. For some applications, however, the stress levels at large strains are critically important. The functional form, which relates the strain and the stress through a power law, based upon these data may be inappropriate. This point will be examined in the next section describing large-strain behavior. 


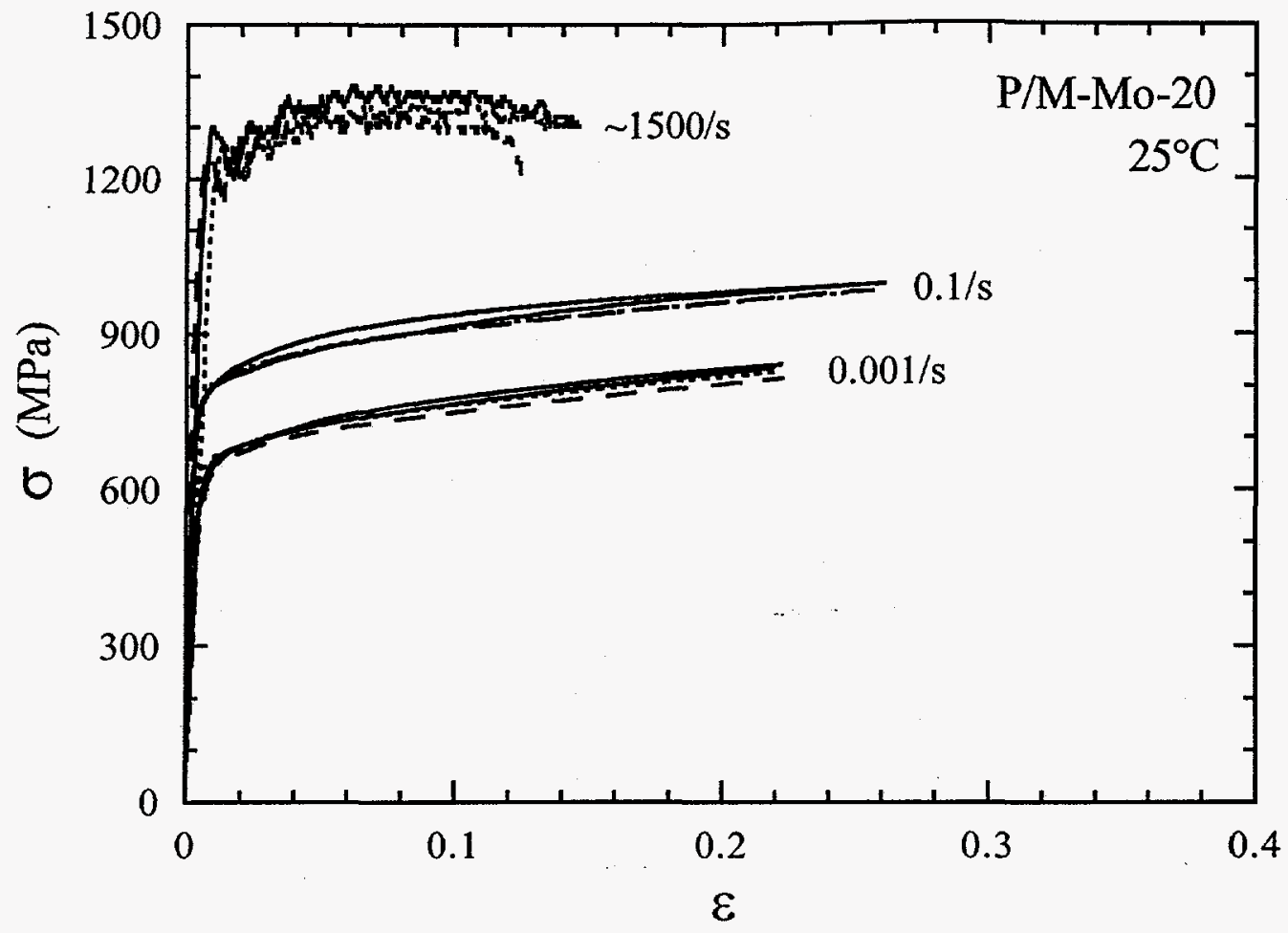

Figure 5: Compressive stress-strain response at room temperature of the P/M-Mo-20 plate material. The samples were machined from three different locations in the plate. Location A- short dashed lines, location B-solid lines, and location C-medium dashed lines.

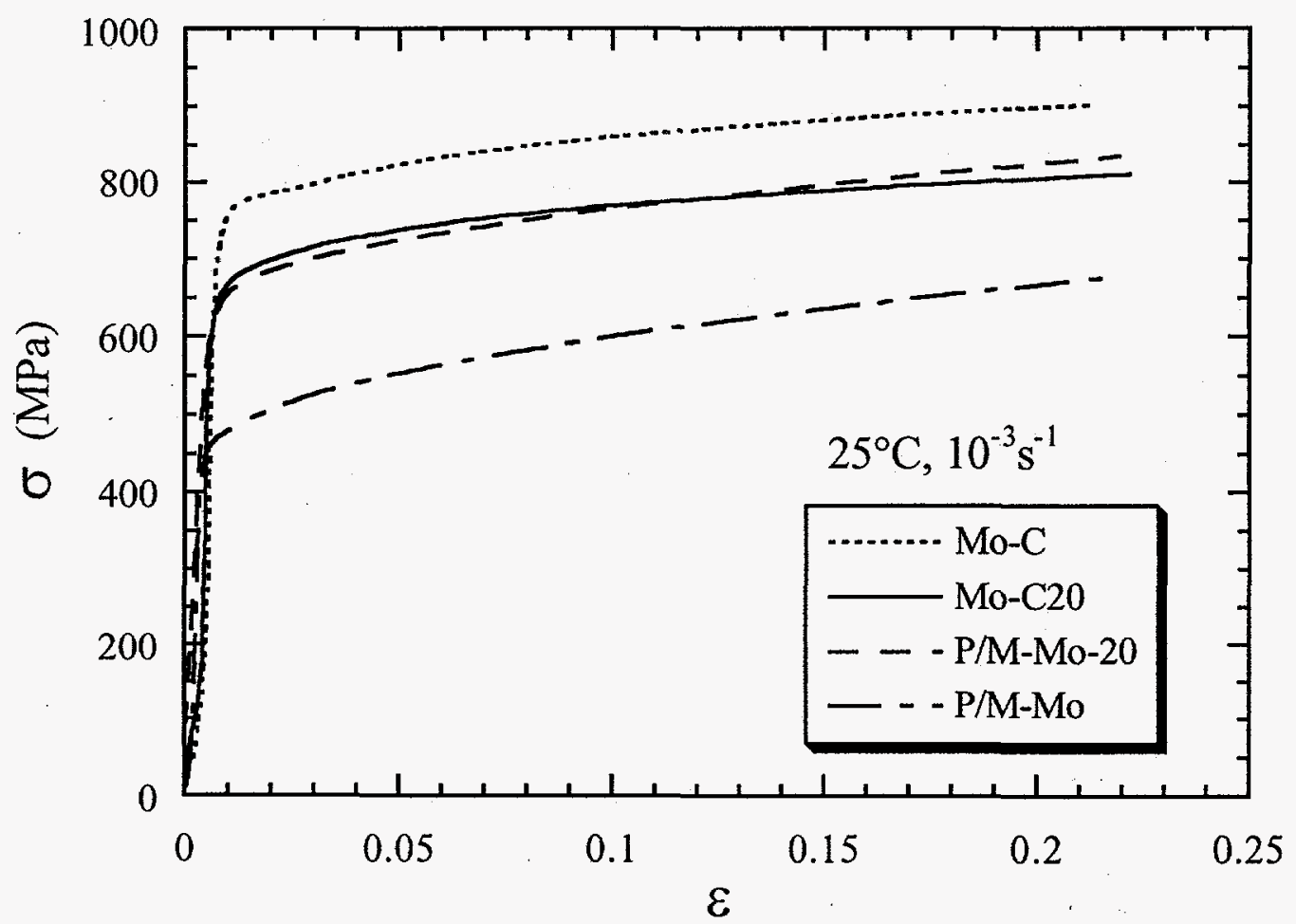

Figure 6: Compressive stress-strain response of four different molybdenums tested at room temperature quasi-statically. 


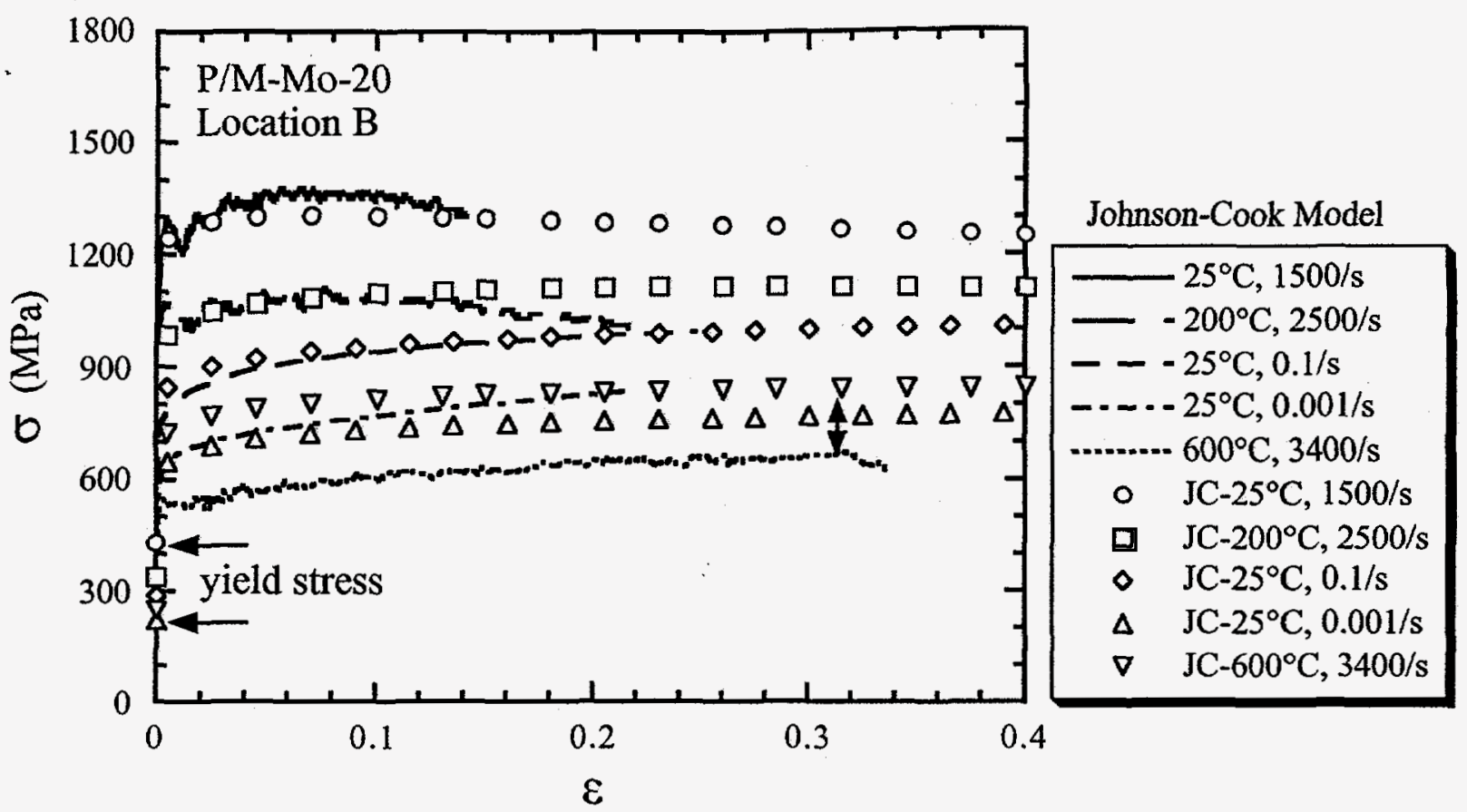

Figure 7: Johnson-Cook model fit (symbols) for the P/M-Mo-20 plate material.

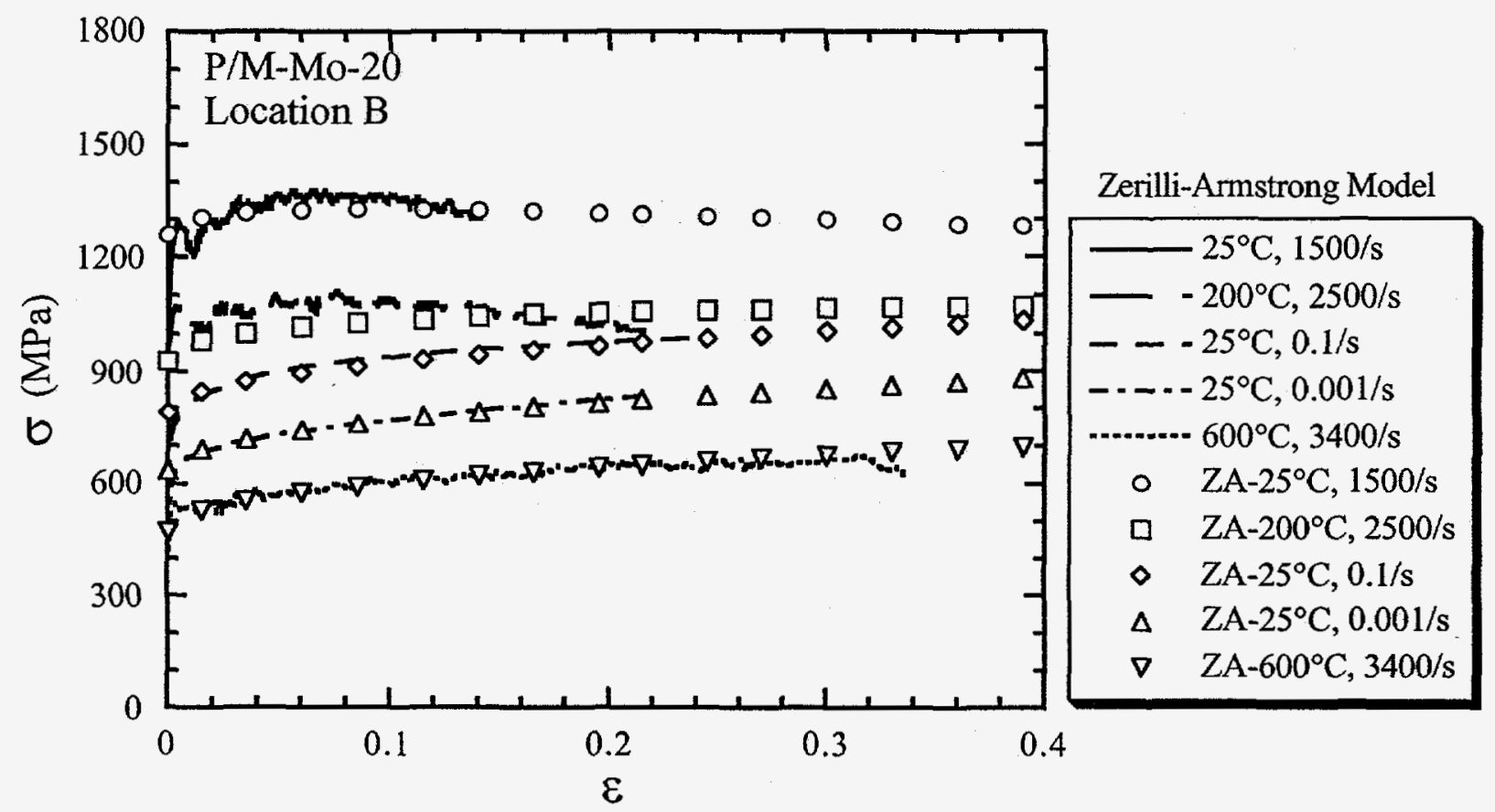

Figure 8: Zerilli-Armstrong model fit (symbols) for the P/M-Mo-20 plate material.

\section{Mechanical Threshold Model:}

For the MTS model, as stated in equation (5), the contributions to the flow stress from different obstacles needs to be examined to allow accurate physically-based materials modeling. The athermal stress depends on the temperature through the shear modulus only and it is a constant after being normalized by the shear modulus. The second term on the right hand side of equation (5) represents the thermal contribution to the yield stress on top of the athermal contribution. It is further assumed that this term does not evolve with strain. These two terms combined were found to capture the yield stresses very well as shown in Fig. 9. The strain hardening part was described 
by equations (6) and (7) using a phenomenological hardening law that eventually saturates at large strains. The work hardening behavior at $25^{\circ} \mathrm{C}$, at $0.1 / \mathrm{s}$ and $0.001 / \mathrm{s}$ was well reproduced by the hardening law adopted in the MTS model within the strain range tested.

The JC model missed the high rate- and temperature-sensitivities of this material while capturing the strain hardening behavior. The ZA and the MTS models satisfactorily described both the yield and hardening behavior of the P/M Mo. All the constitutive model coefficients were derived based on the same well controlled low-strain data as a function of strain rate and temperature. It is interesting to examine how well each of these three models can extrapolate to large strains.

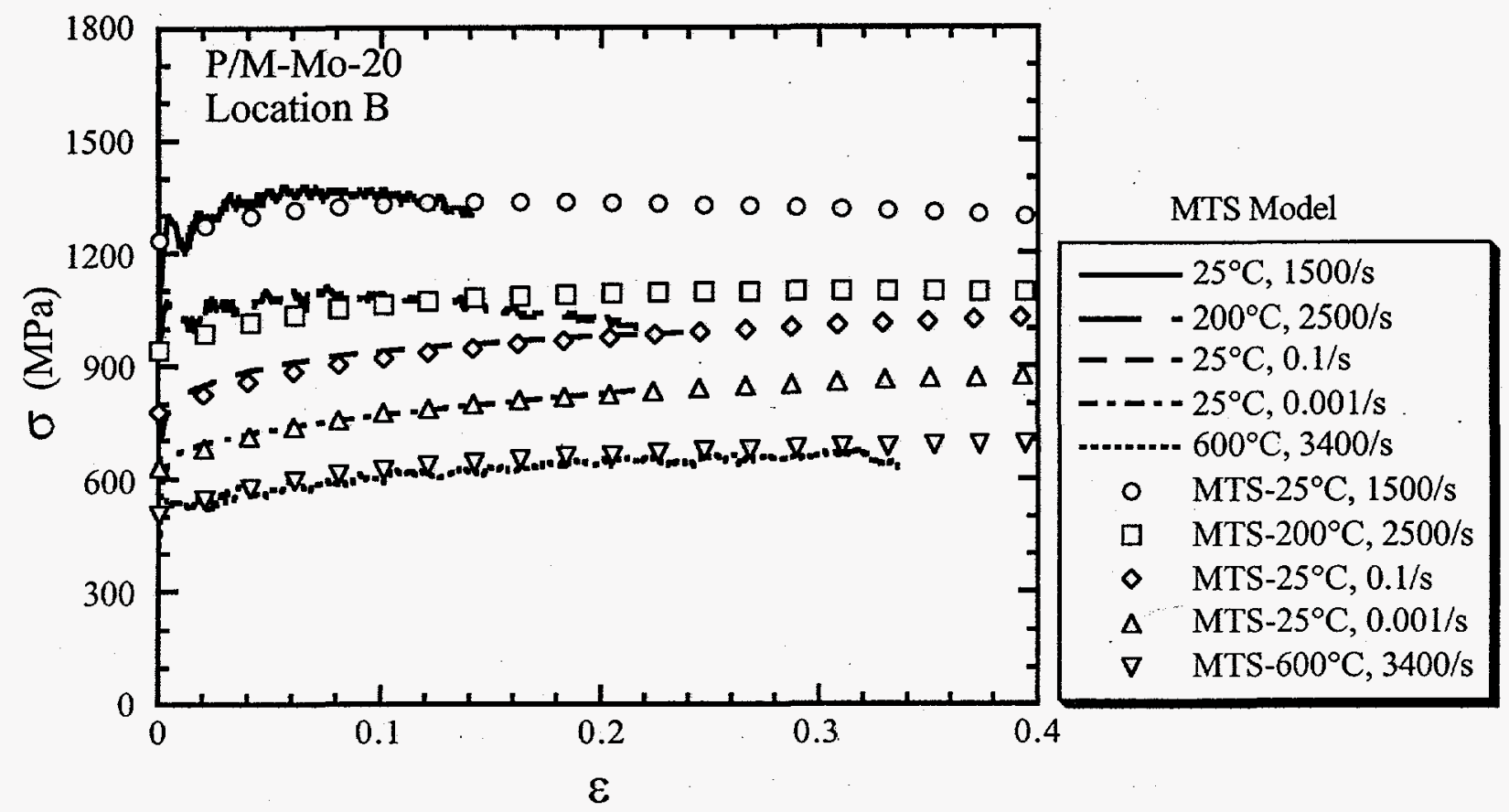

Figure 9: Mechanical Threshold Stress (MTS) model fit (symbols) for the P/M-Mo-20 plate material.

\section{Taylor Cylinder Impact Simulation}

Taylor cylinder impact tests ${ }^{[18,36-39]}$ are relatively easy and inexpensive to perform. Depending on the initial impact velocity and the material strength, a very wide range of strain rates, temperatures (due to adiabatic heating), and strains can be achieved from a single test. The Taylor test provides a clean set of experimental data from which to validate the implementation, and the accuracy of a constitutive model in a large finite element code. A schematic drawing of a Taylor cylinder test and a photograph of the post-test geometry for a tantalum Taylor sample ${ }^{[18]}$ is shown in Fig. 10. The Taylor tests were simulated using the finite element EPIC-95[40] code. An isotropic von Mises yield surface in conjunction with a flow stress model (JC, ZA, or MTS) was used in the calculation. The sample was a 30 caliber $(7.62 \mathrm{~mm}$ diameter) cylinder with a length of $38.1 \mathrm{~mm}$ giving the length-to-diameter ratio $\mathrm{L} / \mathrm{D}=5$. The initial impact velocity was $175 \mathrm{~m} / \mathrm{s}$ in the calculation. The final dimensions from the calculations are listed in Table I and the side profiles are plotted in Fig. 11 for the three constitutive models. The results using the JC and the ZA models in general are harder than that of the MTS model calculation. The deformation zone is seen to be narrower in depth from the impact surface in the MTS model calculation than those of the JC and the ZA models. This is mainly due to the difference between the three models in predicting the flow stresses at large strains. There were two sets of parameters generated for the JC model. The first set was optimized so the $200^{\circ} \mathrm{C}$ flow stress behavior was well described and was listed in the first row of Table I and shown in Fig. 11(a). The model fit plotted with the experimental data are shown in Fig. 7. The second set of parameters was optimized to capture the flow stress at $600^{\circ} \mathrm{C}$. The calculated stress at $200^{\circ} \mathrm{C}$ from this set of data would be lower than the actual experimental data. The Taylor simulation result from the second set of parameters for the JC model is plotted in Fig. 11(b). The overall response in terms of final height and the final Taylor cylinder diameter at 

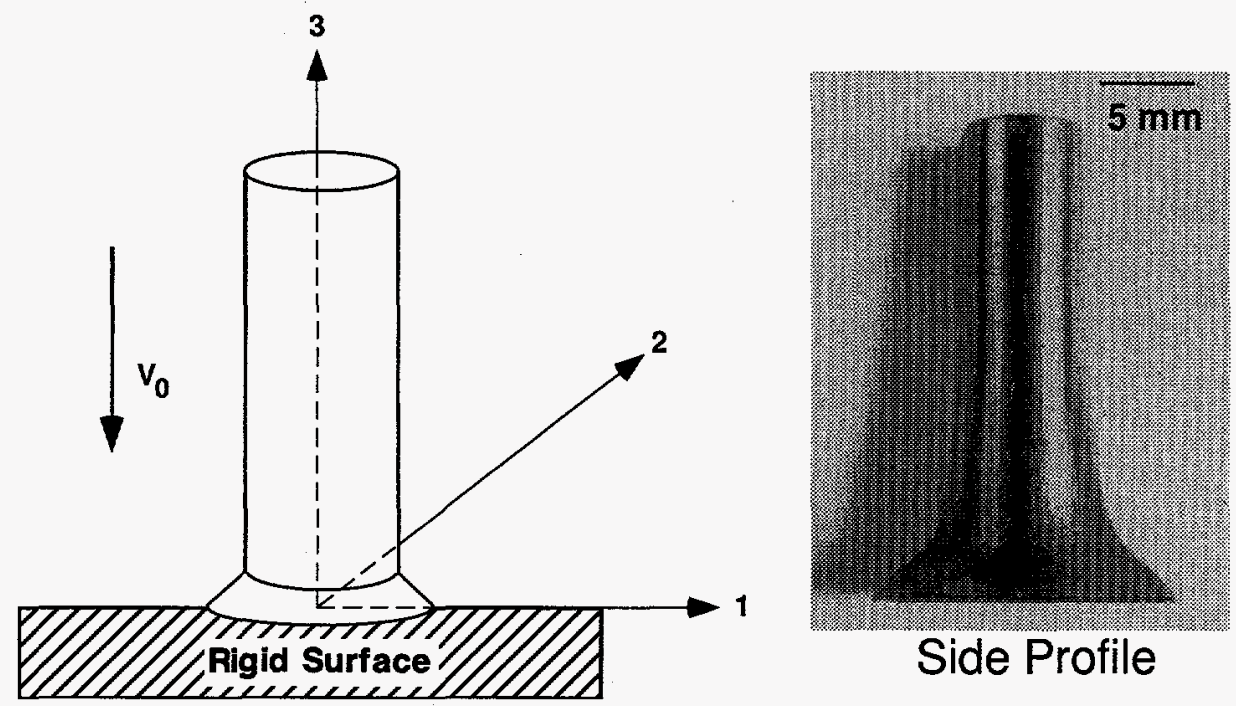

Figure 10: Schematic drawing of a Taylor cylinder impact test (left) and a photograph of the post-test geometry for a tantalum Taylor sample[18] (right).

Table I. Taylor cylinder calculation* results

\begin{tabular}{|l|ccc|}
\hline & Final Length $(\mathrm{mm})$ & Final Diameter $(\mathrm{mm})$ & $\mathrm{D}_{\text {Model }} / \mathrm{D}_{\text {MTS }}$ \\
\hline JC model - fit $200^{\circ} \mathrm{C}$ & 34.95 & 11.39 & 0.877 \\
$\mathrm{JC}$ model - fit $600^{\circ} \mathrm{C}$ & 34.16 & 12.46 & 0.959 \\
ZA model & 35.08 & 11.42 & 0.879 \\
MTS model & 34.49 & 12.99 & 1.000 \\
\hline
\end{tabular}

* Initial length $=38.1 \mathrm{~mm}$, initial diameter $=7.62 \mathrm{~mm}$, initial velocity $=175 \mathrm{~m} / \mathrm{s}$.

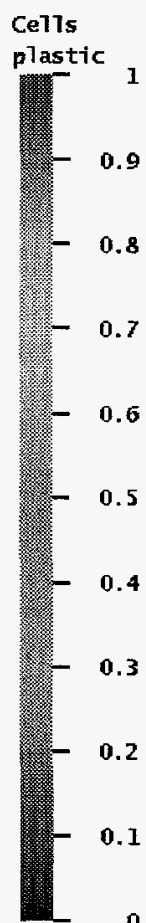

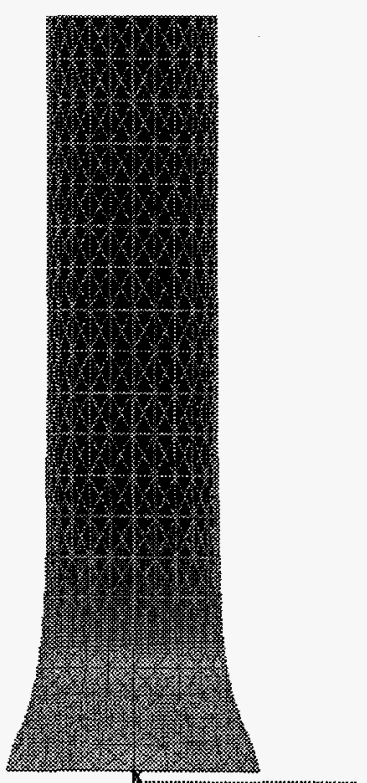

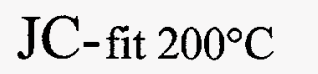

(a)

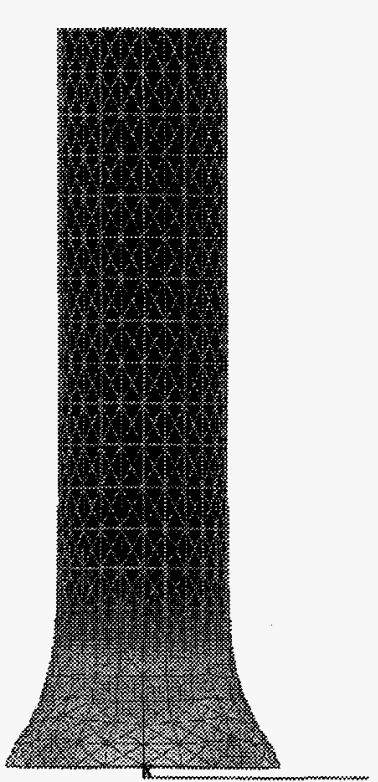

$\mathrm{JC}$-fit $600^{\circ} \mathrm{C}$

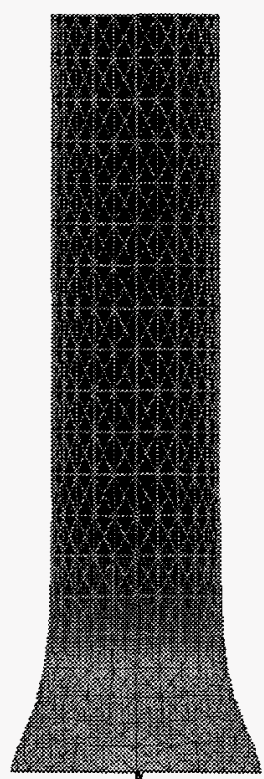

ZA

(c)

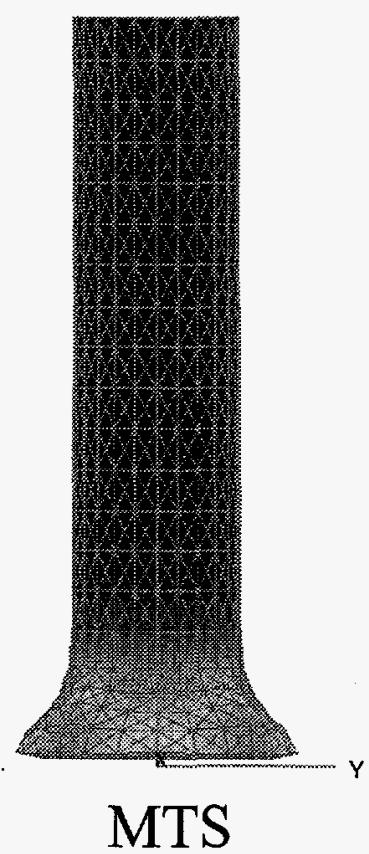

(d)

Figure 11: Comparison of Taylor cylinder impact simulation results among the three constitutive models. 
the impact surface is close to the measurements from the MTS model calculation. However, the depth of the deformation zone and the detail of its shape are not the same. The JC model is suitable to describe a material with a mildly rate-dependent yield strength and mildly to strongly ratedependent work hardening response. As shown for the case of Mo and other bec metals, the type of mechanical response doesn't fall within the range for which the JC model was derived. It is not possible to derive a unique set of parameters for the JC model that is capable of accurately describing the yield and hardening behavior for most bcc metals, for test conditions in the range of $0-2$ in strain, $25-1000^{\circ} \mathrm{C}$ in temperature, and $10^{-3}-10^{4} \mathrm{~s}^{-1}$ in strain rate.

\section{Strain Hardening at High Rate and to Large Strains}

There are two questions which remain to be answered in order to complete the derivation of the constitutive model parameters. The first one is what is the actual strain hardening behavior at high strain rates and how to obtain it, and the second question is what is the mechanical response at large strains and how to describe it. An isothermal stress-strain curve at high strain rate was obtained via incremental tests on a Hopkinson bar for tantalum ${ }^{8]}$. An attempt was made to reload the sample after being deformed at $25^{\circ} \mathrm{C}$ at $1500 / \mathrm{s}$ under the same strain rate and the same initial temperature. The first and second loading stress-strain curves are shown in Fig. 13. Comparing the reloading (after the sample returned to room temperature) flow stress level to the stress at the end of the first compression, it is clear that significant thermal softening due to adiabatic heating from the plastic work occurred at the early part of deformation. The strain rate versus strain profile from the reloading using the Hopkinson bar was however not a perfect one. Due to further work hardening in the sample and its change in dimension, it was difficult to control the second test at the same strain rate as the previous one and to maintain a constant strain rate to large strains in the sample.

As stated in the previous section, namely description of models, plastic deformation is controlled by the thermal-activated interactions of dislocations with obstacles. In the thermally activated glide regime, the interaction kinetics for short range obstacles are described by an Arrhenius expression of the form[6,9-14]:

$$
\dot{\varepsilon}=\dot{\varepsilon}_{0} \exp \left(\frac{-\Delta G}{k T}\right)
$$

The strain rate and temperature are therefore interchangeable such that different combinations will yield the same thermal activation energies. It is expected that under those circumstances, the overall mechanical responses would be very similar as long as the controlling deformation mechanism is dominated by thermal-activated processes. Based on this idea, a low-temperature compression fixture was built for an MTS servo-hydraulic test frame capable of performing tests at temperatures between -180 and $25^{\circ} \mathrm{C}$ and at strain rates between $10^{-5}$ and $10 / \mathrm{s}$. The temperature is controlled by regulating the amount of liquid nitrogen flowing through channels inside the platens (Fig. 12) and was found to be accurate within $\pm 1^{\circ} \mathrm{C}$.

Thermal softening resulted from adiabatic heating at high strain rate made the determination of the hardening behavior difficult. In the previous section of constitutive modeling, according to the past experience with bcc metals ${ }^{[18]}$ the overall strain hardening behavior was obtained from a quasi-static test at $25^{\circ} \mathrm{C}$ at $0.1 / \mathrm{s}$ where adiabatic heating is minimized. Figure 13 shows four quasistatic tests from $77 \mathrm{~K}$ to $298 \mathrm{~K}$. The strain hardening rates are not a strong function of temperature except at $77 \mathrm{~K}$ where twinning may occur at such low temperature. The flow stress at $298 \mathrm{~K}$ at $0.1 / \mathrm{s}$ can be considered to be parallel to the "isothermal" stress/strain response at high rate (by connecting the $5-10 \%$ of strain from the first deformation to the data from reloading). At $183 \mathrm{~K}$, the quasi-static stress/strain behavior is very close to that of dynamic test at room temperature. This substantiates the applicability of thermal-activation theory to the P/M-Mo investigated. The stress/strain response at $133 \mathrm{~K}$ is similar to that which would be achieved if extrapolating the strain rates to $10^{5} \mathrm{~s}^{-1}$ at room temperature supports the assumption that the strain hardening rate is insensitive to the temperature for the $\mathrm{P} / \mathrm{M}$-Mo plate studied. The quasi-static low temperature tests therefore provide an alternative to obtain the strain hardening behavior at high rate under a better controlled test condition. 


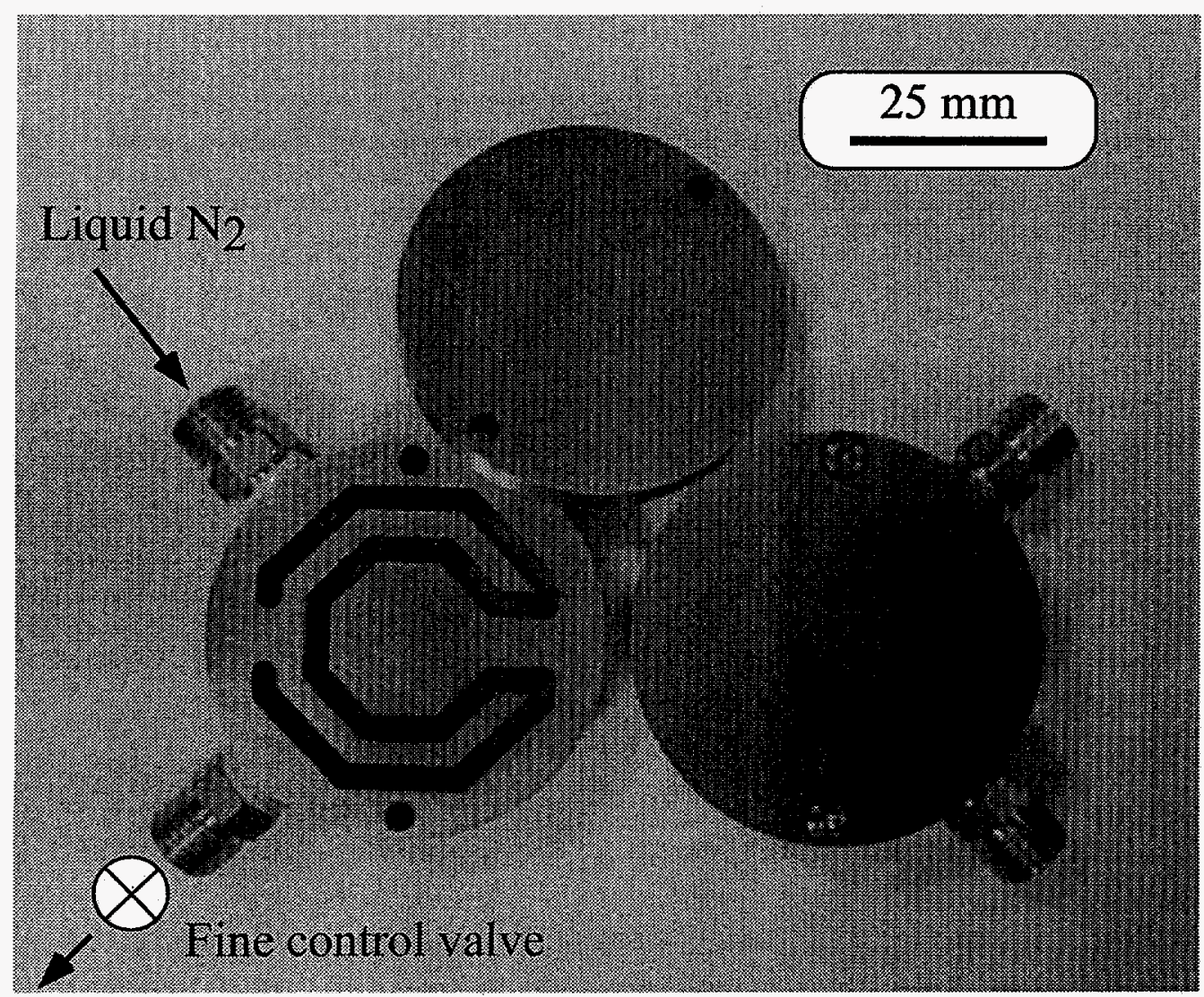

Figure 12: Low-temperature fixture for a quasi-static loading frame.

After establishing a method to measure the strain hardening behavior suitable for both quasi-static and dynamic conditions, the flow stress at large strains is of particular interest for modeling the Taylor cylinder impact test as well as some defense applications. The samples at 298 and at $183 \mathrm{~K}$ were reloaded incrementally with intermittent re-lubrication to large strains. The data up to strains of 0.8 are plotted in Fig. 14. The strain hardening behavior seems to be insensitive to the temperature at large strains. With large-strain data, the accuracy of predicting the flow stress by the constitutive models discussed previously is evaluated. The mechanical threshold stress (MTS) model fit (filled circles) and the Zerilli-Armstrong (ZA) model fit (open triangles) for the P/M-Mo20 plate material calculated to large strains are plotted with the experimental data in Fig. 15 . The MTS model accurately capture the yield stress and the work hardening at low strains and then satisfactorily follows the experimental flow stress data to large strains. The ZA model (as well as JC model) when fitted correctly to the small-strain data, over-predicts the flow stress at large strains due to its use of a power-hardening law. This is the major factor that accounts for the difference in the Taylor cylinder calculations shown in Figs. 11 (c) and (d) for the ZA and the MTS models, respectively. The degree of difference can be alleviated by re-fitting the ZA model to

include the data at large strains to lower the hardening coefficient " $n$ " in equation (2) to capture the flow stress at large strains (diamonds in Fig. 15). In this new fit, the yield and flow stresses up to strain of 0.1 are missed as displayed in Fig. 15. The severeness of the misfit increases for annealed metals whose work hardening rates are too complicated for a power-hardening law to handle[41]. The phenomenological based hardening law (equation (6)) seems to capture the hardening behavior accurately in the small-strain regime and further "predict" the flow stress behavior at large strains reasonably well[35,41,42]. 


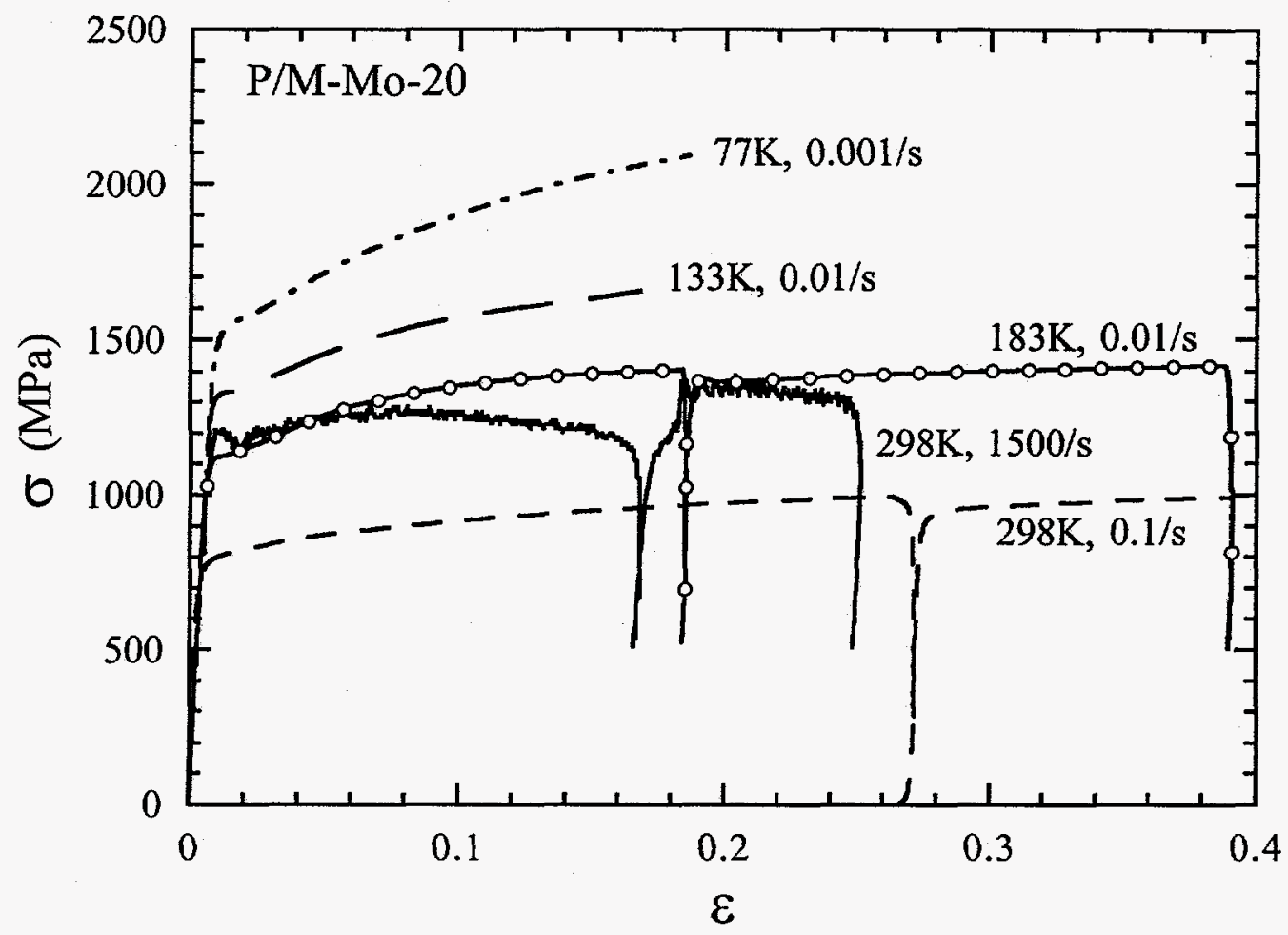

Figure 13: Compressive stress-strain response of the P/M-Mo-20 plate material. Several test conditions were carried out to acquire the hardening behavior at high strain rate.

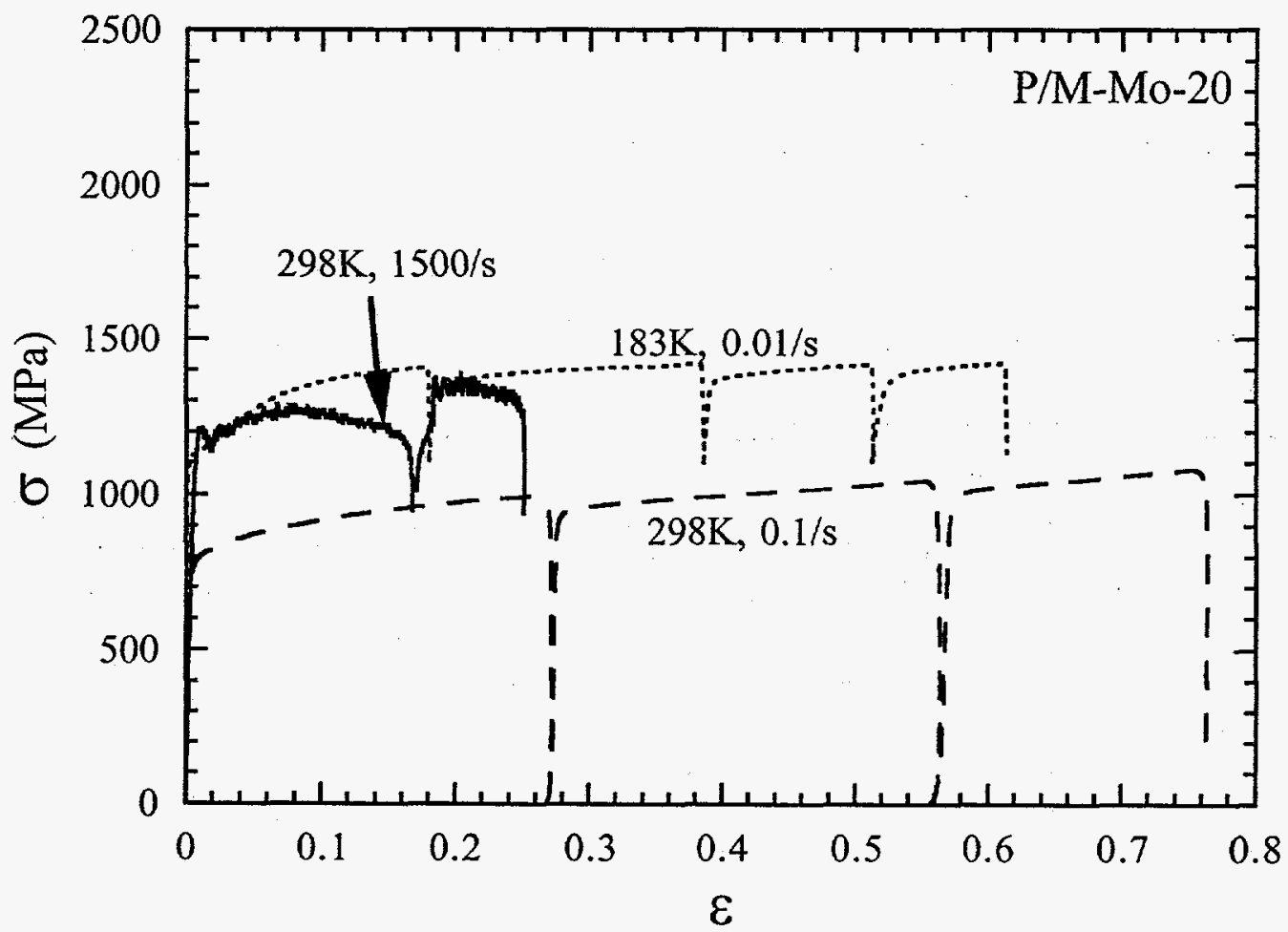

Figure 14: Compressive stress-strain response of the $\mathrm{P} / \mathrm{M}-\mathrm{Mo}-20$ plate material to large strains through several incremental tests with intermittent relubrication. 


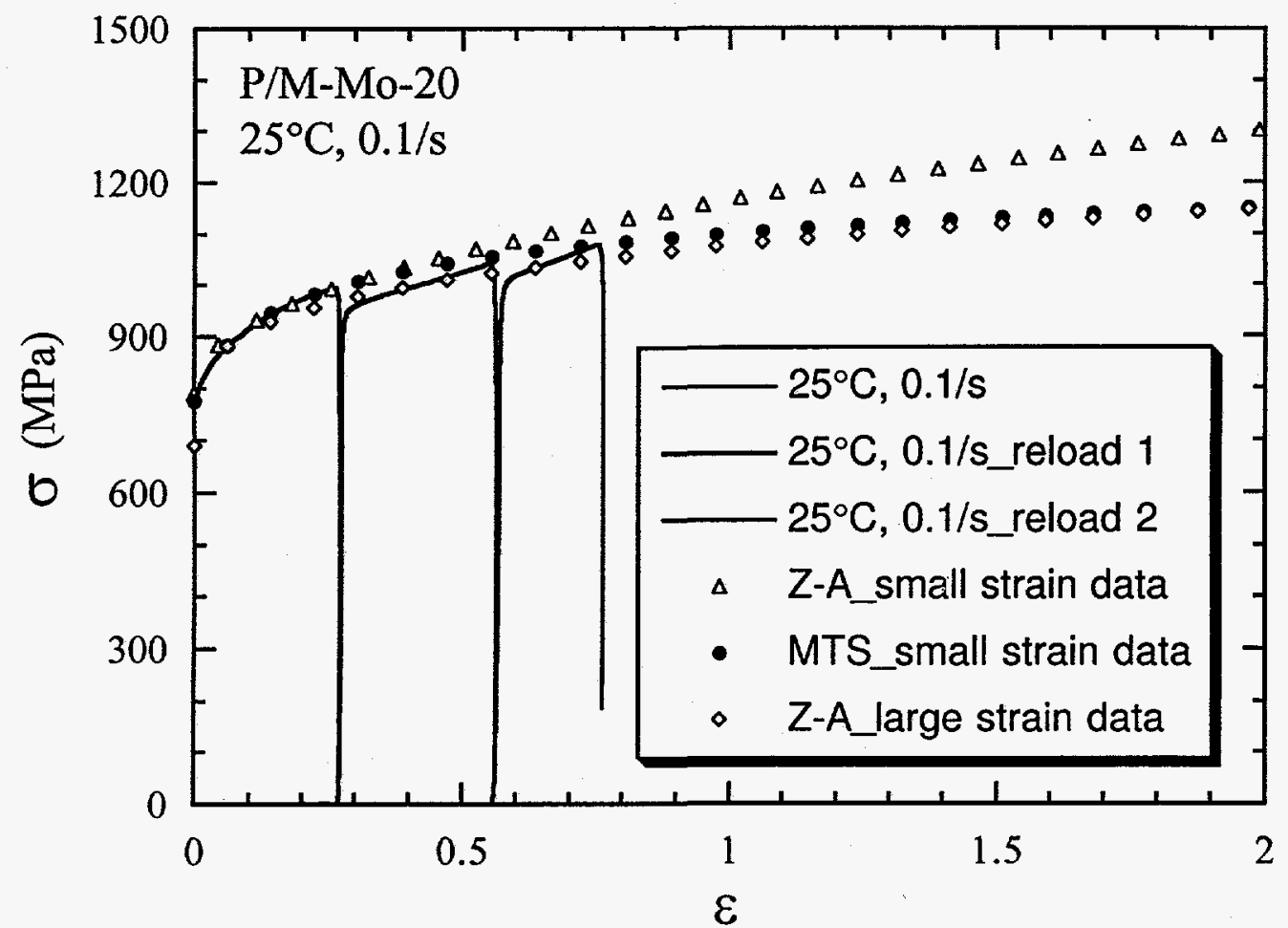

Figure 15: Mechanical Threshold Stress (MTS) model fit (closed symbols) and two ZerilliArmstrong (ZA) model fits (open symbols) for the P/M-Mo-20 plate material to large strains. The ZA model was fitted to small strains only (triangles) and to including large strains (diamonds).

\section{Summary}

The current study of the mechanical properties and constitutive relations for molybdenum under high strain-rate deformation yields the following observations:

(1). The high strain-rate and temperature sensitivity of the flow stress and the insensitivity of the strain hardening rate indicate that the rate controlling mechanism for deformation of Mo at high strain rate from low to intermediate temperatures is thermal activation over a high Peierls stress.

(2). Quasi-static low temperature tests provide an alternative to obtain the strain hardening behavior at high strain rate to large strains under a better controlled test conditions.

(3). Three constitutive relations, namely the Johnson-Cook (JC), the Zerilli-Armstrong (ZA), and the Mechanical Threshold Stress (MTS) models, have been examined to describe stress-strain rate-temperature relations of Mo-plate in the high strain rate regime. The empirical relations used in the JC and ZA models for strain hardening $\left(\sigma_{0}+K \cdot \varepsilon^{n}\right)$ may introduce substantial deviations from the actual stress levels at large strains if the coefficients were derived from low-strain data. The physically-based MTS model overall is seen to provide better fitting results for a wider range of strains. The comparison from Taylor cylinder impact test simulations indicates the significance of accurately capturing the large-strain behavior as well as the temperature and strain-rate sensitivities.

\section{Acknowledgments}

The authors acknowledge the assistance of M.F. Lopez, R.W. Carpenter II, and C.M. Cady for conducting the mechanical tests. This study was carried out under the auspices of the U.S. Department of Energy. 


\section{References}

1. E.L. Baker, A. Daniels, G.P. Voorhis, and T. Vuong: Development of Molybdenum Shaped Charge Liners, elsewhere in this volume, 1998.

2. K.G. Hoge and A.K. Mukherjee: The Temperature and Strain Rate Dependence of the Flow Stress of Tantalum, J. Mater. Sci., 1977, vol. 12, pp. 1666-1672.

3. J.W. Christian: Some Surprising Features of the Plastic Deformation of Body-Centered Cubic Metals and Alloys, Metall. Trans., 1983, vol. 14A, pp. 1237-1256.

4. G.T. Gray III and A.D. Rollett: The High-Strain-Rate and Spallation Response of Tantalum, Ta-10W, and T-111, High Strain Rate Behavior of Refractory Metals and Alloys, R. Asfhani, E. Chen, and A. Crowson, eds., TMS, Warrendale, PA, 1992, pp. 303-315.

5. R.A. Foxall and C.D. Statham: Dislocation Arrangements in Deformed Single Crystals of Niobium-Molybdenum Alloys and Niobium-9at.\% Rhenium, Acta metall., 1970, vol. 18, pp. 1147-1158.

6. U.F. Kocks, A.S. Argon, and M.F. Ashby: Thermodynamics and Kinetics of Slip, Progress in Materials Science, Vol. 19, Pergamon Press, New York, 1975.

7. R.J. Arsenault and A. Lawley: Work-Hardening Characteristics of Ta and Ta-base Alloys, Work Hardening, J.P. Hirth and J. Weertman, eds., Gordon and Breach, New York, 1968, pp. 283-309.

8. C.M. Lopatin, C.L. Wittman, J.P. Swensen, and P.F. Perron: Dependency of Strain Rate Path of Mechanical Properties of Tantalum in Compression, High Strain Rate Behavior of Refractory Metals and Alloys, R. Asfahani, E. Chen, and A. Crowson, eds., The Minerals, Metals \& Materials Society, Warrendale, Pennsylvania, 1992, pp. 241-247.

9. A. Seeger: Theorie der Kristallplastizität: I. Grundzüge der Theorie, Z. Naturforschg., 1954, vol. 9A, pp. 758-775.

10. A. Seeger: Theorie der Kristallplastizität: II. Die Grundstruktur der dichtest gepackten Metalle und ihr Einfluß auf die plastische Verformung, Z. Naturforschg., 1954, vol. 9A, pp. 856869.

11. A. Seeger: Theorie der Kristallplastizität: III. Die Temperatur-und Geschwindigkeitsabhängigkeit der Kristallplastizität, Z. Naturforschg., 1954, vol. 9A, pp. 870-881.

12. H. Conrad: Thermally Activated Deformation of Metals, J. Metals, 1964, vol. 16, pp. 582588.

13. R. Becker: Über die Plastizität amorpher und kristalliner fester Körper, Physikalische Z., 1925, vol. 26, pp. 919-925.

14. E. Orawan: Zur Kristallplastizität I. Tieftemperaturplastizität und Beckersche Formel, $Z$. Physik, 1934, vol. 89, pp. 605-613.

15. P.J. Maudlin, R.F. Davidson, and R.J. Henninger: Implementation and Assessment of the Mechanical-Threshold-Stress Model Using the EPIC2 and PINON Computer Codes, ReportLA-11895-MS, Los Alamos National Laboratory, 1990.

16. M.N. Raftenberg: Modeling RHA Plate Perforation by a Shaped Charge Jet, Report-BRLTR-3363, U.S. Army Ballistic Research Laboratory, 1992.

17. A.M. Rajendran and P. Woolsey: Penetration of Tungsten Alloy Rods Into Shallow-Cavity Steel Targets, Report-ARL-TR-216, U.S. Army Research Laboratory, 1993.

18. P.J. Maudlin, J.F. Bingert, J.W. House, and S.R. Chen: On the Modeling of the Taylor Cylinder Impact Test for Orthotropic Textured Materials: Experimental and Simulations, International J. Plasticity, 1998, in press.

19. P.S. Follansbee and U.F. Kocks: A Constitutive Description of Copper Based on the Use of the Mechanical Threshold Stress as an Internal State Variable, Acta metall., 1988, vol. 36, pp. 81-93.

20. G.R. Johnson and W.H. Cook: A Constitutive Model and Data for Metals Subjected to Large Strains, High Strain Rates and High Temperatures, Proceedings of the Seventh International Symposium on Ballistic, The Hague, The Netherlands, 1983, pp. 541-547.

21. F.J. Zerilli and R.W. Armstrong: Dislocation-mechanics-based Constitutive Relations for Material Dynamics Calculations, J. Appl. Phys., 1987, vol. 61, pp. 1816-1825.

22. P.S. Follansbee: High Strain Rate Compression Testing - The Hopkinson Bar, 9th edn. Vol. 8, Am. Soc. Metals, Metals Park, Ohio, 1985, pp. 198-203.

23. P.S. Follansbee and G.T. Gray III : An Analysis of the Low Temperature and High-StrainRate Deformation of Ti-6Al-4V, Metall. Trans. A, 1989, vol. 20A, pp. 863-874. 
24. P.S. Follansbee, J.C. Huang, and G.T. Gray III : Low-Temperature and High-Strain-Rate

- Deformation of Nickel and Nickel-Carbon Alloys and Analysis of the Constitutive Behavior According to An Internal State Variable Model, Acta metall., 1990, vol. 38, pp. 1241-1254.

25. S.R. Chen and G.T. Gray III : Constitutive Behavior of Tungsten and Tantalum: Experiments and Modeling, 2nd International Conference on Tungsten and Refractory Metals, A. Bose and R.J. Dowding, eds., October 17-19, McLean, VA, Metal Powder Industries Federation, Princeton, New Jersey, 1995, pp. 489-498.

26. U.F. Kocks: Laws for Work-Hardening and Low-Temperature Creep, J. Eng. Mater. Tech., Trans. ASME, 1976, vol. 98, pp. 76-85.

27. P. Hassen: Plastic Deformation of Nickel Single Crystals at Low Temperatures, Phil. Mag., 1958, vol. 3, pp. 384-418.

28. G. Schoeck and A. Seeger: Defects in Crystalline Solids, Physical Society, London, 1955.

29. G. Simmons and H. Wang: Single Crystal Elastic Constants and Calculated Aggregate Properties: A Handbook, 2nd edn., The M.I.T. Press, Boston, Mass., 1991.

30. Y.P. Varshni: Temperature Dependence of the Elastic Constants, Phys. Rev. B, 1970, vol. 2, pp. 3952-3958.

31. D.R. Stull and G.C. Sinke, eds.: Thermodynamic Properties of the Elements, American Chemical Society, Washington D. C., 1956.

32. S.R. Chen and U.F. Kocks: High-Temperature Plasticity in Copper Polycrystals, High Temperature Constitutive Modeling - Theory and Application, A.D. Freed and K.P. Walker, eds., Atlanta, GA, The American Society of Mechanical Engineers, 1991, pp. 1-12.

33. U.F. Kocks and S.R. Chen: On the Two Distinct Effects of Thermal Activation on Plasticity: Application to Nickel, phys. stat. sol. (a), 1992, vol. 131, pp. 403-413.

34. U.F. Kocks, S.R. Chen, and H. Mecking: Is There a Unique Effective Interaction Profile for Dislocations, Advances in Crystal Plasticity, D.S. Wilkinson and J.D. Embury, eds., Kingston, Ontario, Canada, Canadian Institute of Mining, Metallurgy and Petroleum, 1992, pp. 87-112.

35. S.R. Chen and G.T. Gray III : Constitutive Behavior of Tantalum and Tantalum-Tungsten Alloys, Metall. Trans. A, 1996, vol. 27A, pp. 2994-3006.

36. E.H. Lee and S.J. Tupper: Analysis of Plastic Deformation in a Steel Cylinder Striking a Rigid Target, J. Appl. Mech., 1954, vol. 21, p. 63.

37. J.B. Hawkyard: A Theory for the Mushrooming of Flat-Ended Projectiles Impinging on a Flat Rigid Anvil, Using Energy Considerations, Int. J. Mech. Sci., 1969, vol. 11, p. 313.

38. G.R. Johnson and T.J. Holmquist: Evaluation of Cylinder-Impact Test Data for Constitutive Model Constants, J. Appl. Phys., 1988, vol. 64, pp. 3901-3910.

39. C.S. Ting: Constitutive Modeling of Tantalum Dynamic Plasticity Based on the Theory of Thermal Activation and the Evolution of Strain Hardening, High Strain Rate Behavior of Refractory Metals and Alloys, R. Asfahani, E. Chen, and A. Crowson, eds., The Minerals, Metals \& Materials Society, Warrendale, Pennsylvania, 1992, pp. 249-265.

40. G.R. Johnson, R.A. Stryk, T.J. Holmquist, and S.R. Beissel: User Instructions for the 1997 Version of the EPIC Code, Report-WL-TR-1997-7037, Wright Laboratory, Armament Directorate, Eglin Air Force Base report, 1997.

41. S.R. Chen and G.T. Gray III : Comparison Between the Mechanical Threshold Stress (Strength) Model and the New Zerilli-Armstrong Model, Report-LA-UR-96-3534, Los Alamos National Laboratory, 1996.

42. S.R. Chen, G.T. Gray III, and S.R. Bingert: Mechanical Properties and Constitutive Relations for Tantalum and Tantalum Alloys under High-Rate Deformation, Tantalum, The Minerals, Metals, \& Materials Society, 1996, pp. 173-184. 